\title{
Distress in delirium: causes, assessment and management
}

\author{
Sophie T. Williams ${ }^{1}\left[\right.$. Jugdeep K. Dhesi ${ }^{1,2}$ - Judith S. L. Partridge ${ }^{1,2}$
}

Received: 22 July 2019 / Accepted: 25 November 2019 / Published online: 9 December 2019

(c) The Author(s) 2019

\section{Key Summary points}

Aim Distress in delirium causes significant morbidity for patients and their relatives, but it remains under recognised.

Findings This review discusses the current literature regarding distress in delirium: its aetiology, available assessment tools and potential avenues for management.

Message The distress experienced in delirium has long-term psychological effects on patients and their carers, and requires greater understanding and acknowledgement in clinical practice.

\begin{abstract}
Purpose Delirium is a common clinical syndrome associated with increased physical and psychological morbidity, mortality, inpatient stay and healthcare costs. There is growing interest in understanding the delirium experience and its psychological impact, including distress, for patients and their relatives, carers and healthcare providers.

Methods This narrative review focuses on distress in delirium (DID) with an emphasis on its effect on older patients. It draws on qualitative and quantitative research to describe patient and environmental risk factors and variations in DID across a number of clinical settings, including medical and surgical inpatient wards and end of life care. The article provides an overview of the available distress assessment tools, both for clinical and research practice, and outlines their use in the context of delirium. This review also outlines established and emerging management strategies, focusing primarily on prevention and limitation of distress in delirium.

Results Both significant illness and delirium cause distress. Patients who recall the episode of delirium describe common experiential features of delirium and distress. Relatives who witness delirium also experience distress, at levels suggested to be greater than that experienced by patients themselves. DID results in long-term psychological sequelae that can last months and years. Preventative actions, such pre-episode educational information for patients and their families in those at risk may reduce distress and psychological morbidity.

Conclusions Improving clinicians' understanding of the experience and long term psychological harm of delirium will enable the development of targeted support and information to patients at risk of delirium, and their families or carers.
\end{abstract}

Keywords Distress · Delirium · Surgery

\section{Introduction}

Delirium describes a clinical syndrome comprising of disturbed cognitive function and altered consciousness with acute onset or fluctuating nature [1]. It is a common clinical syndrome, especially in older, acutely unwell, end of life

Sophie T. Williams

sophie.1.williams@kcl.ac.uk

1 Perioperative Medicine for Older People Undergoing Surgery (POPS), Department of Ageing and Health, St Thomas' Hospital, Westminster Bridge Road, London, UK

2 Primary Care and Public Health Sciences, Faculty of Life Sciences and Medicine, King's College London, London, UK or post-operative patients, with up to $22 \%$ of adult medical inpatients experiencing delirium [2]. Delirium contributes significantly to increased morbidity, both physical and psychological, as well as mortality, inpatient stay and healthcare costs [3-5]. There is growing interest in understanding the delirium experience and its psychological impact for 
patients and their relatives, carers and healthcare providers. This review focuses on distress in delirium (DID), its risk factors, assessment and management options and details current approaches in understanding this intersection of mental and physical health in the older population.

The literature investigating delirium experience spans a range of clinical environments, from hospital settings including the emergency department [6], intensive care unit (ICU) [7-11], inpatient oncology [12,13], and surgical units [14-17] to community services such as nursing homes [18, 19] and hospices [20, 21].

While only some patients recall delirium, those who do and their relatives who witness it can experience significant distress and psychological morbidity. This review considers a broad definition of distress, including descriptions of anxiety, depression and PTSD resulting from a delirium episode. Examining associations between patient factors and features of delirium is useful for understanding who is at risk of DID.

Original research and review articles written in English were identified from Ovid, MEDLINE, PsychINFO, and PubMed databases between 1980 and 2019 using the terms 'delirium' and 'distress', 'anxiety', 'depression' or 'PTSD'. These were then considered by the authors for relevance, content and impact. This is a narrative review, considering a broad range of articles relevant to understanding distress in delirium, and not a systematic review.

\section{Causes of distress in delirium}

\section{Patient factors}

Patient-specific factors influencing DID can be divided into risk factors common across healthcare settings and those specific to certain demographics or interventions.

The extent of critical illness and physiological insult contributes to DID. There is a high incidence of delirium in intensive care with figures reported up to $87 \%$ among patients surviving coma [22]. Multiple factors relating to critical illness, ICU admission and treatment are known to cause delirium: length of ICU admission, sedative use, analgesic control, infection with fever, renal failure, surgery $[9,23,24]$. Evidence shows that delirium in this setting is associated with psychological morbidity, including symptoms of Post-traumatic Stress Disorder (PTSD), anxiety and depression $[10,25]$, and that acute psychological reactions in ICU are a strong risk factor for psychological morbidity at 3 months [26, 27].

It is difficult to distinguish the contribution that delirium, as opposed to critical illness, makes to perception of distress and to disentangle these factors in the literature [28]. However, persistent delusional memories at 3 months are associated with development of PTSD, independent of illness severity, suggesting that the presence of delirium may in itself be an independent cause of distress [10]. Similarly, worse functional status correlates with heightened DID. For cancer patients who recalled their delirium, reduced Karnofsky performance $(<30)$ positively correlated with distress severity [12].

While cognitive impairment, dementia and older age are risk factors for developing delirium [29], there is insufficient evidence as to whether these influence recall of delirium and therefore risk of DID. A qualitative study examining adults over the age of 65 undergoing hip surgery showed that patients with lower preoperative Mini Mental State Examination scores were less likely to recall the delirious episode [14]. However, this has not been supported by other studies [17, 12]. It cannot be assumed that because a patient is older, or has cognitive impairment, they will suffer any less from DID.

Delirium is common at the end of life. DID in palliative care or hospice settings has been explored most by characterising experience of distress by relatives and healthcare staff [21, 30, 31], in part because patients themselves do not survive to be able to recall their delirium or distress. Impact on carers is discussed later in this review.

\section{Delirium factors}

The phenotypic features of delirium and association with DID vary between clinical settings. This reflects heterogeneity in the patient groups and in the tools used to assess and label psychiatric presentations in delirium. In cancer inpatients assessed using The Memorial Delirium Assessment Scale (MDAS) [32], time/space disorientation, visual disturbances, delusions and psychomotor agitation were associated with increased distress. However only delusions [12] and psychomotor agitation [13] were independent predictors of severity of distress. In a postoperative cohort, delusions, abnormal thought processes, labile affect, language disturbance, agitation and disorientation as assessed using the Delirium Rating Scale (DRS) were associated with increased DID [17,33], while orientation and thought disorder inversely correlated with extent of distress.

Intuitively, it might be thought that DID would differ between delirium subtypes. However, the available evidence suggests subtype of delirium (hyperactive, hypoactive or mixed) makes no difference to the extent of DID [12, 13, 17]. This has important clinical implications: hypoactive delirium is both more prevalent and at the same time underdiagnosed [16]. Patients with hypoactive delirium may not overtly display agitation, but it is likely they experience the same level of distress, and psychological morbidity as those patients with hyperactive delirium.

Severity of DID is associated with extent of recall of the delirium episode. While in some studies this has been 
assumed, it has been shown explicitly for post-operative surgical patients, cancer patients and inpatients diagnosed with delirium [13, 17, 34]. Breitbart et al. [12] found that the rates of recall of delirium were inversely proportional to severity of delirium. ICU patients diagnosed with delirium during their admission, report lower rates of recall suggesting the episode of delirium may have been more severe [35]. Furthermore, delusional recall is a contributing factor to anxiety, depression and PTSD [10, 11].

Duration of delirium is an independent predictor of subsequent severity of global cognition and executive dysfunction [36]. Furthermore, delirium can have a impact on cognitive trajectory, both in patients with diagnosed neurodegenerative disease and older patients without any clinical evidence of neurodegenerative disease [37-39]. Duration of delirium is also associated with distress as shown in a mixed population of surgical patients followed up at 12 months [17].

\section{Assessment of distress in delirium}

Many assessment tools to identify distress have been developed: 45 different scales/scores exist for assessing depression and or distress in cancer patients alone [40]. However, few have been used in research or clinical practice of DID, as discussed below. The mixed aetiology of distress makes quantifying one single contributing factor impossible and so distress scores are often used in conjunction with pathologyspecific assessment tools, depending upon the clinical area. Currently, there is no consensus on which assessment tool should be used to measure DID.

\section{Measuring distress in clinical practice}

The Hospital Anxiety and Depression Score (HADS) is an established assessment tool to examine self-reported symptoms of anxiety and depression among inpatients [41, 42], patients in the community and the general population [43], independent of physical symptoms. The HADS comprises 14 questions and has been used extensively in clinical practice and research. Tools with more than eight questions have been attributed better diagnostic accuracy and diagnostic validity. However, with more questions and time taken to complete, there is a recognised diminishing return: in one questionnaire survey, fewer than ten percent of oncologists were prepared to use full anxiety assessments, including HADS, in their clinical practice [44]. With respect to assessing DID, its length, focused nature and lack of specificity to delirium symptoms make the HADS less appropriate for assessing patients during an episode of delirium.

The Distress Thermometer is a brief self-assessment tool developed by the US National Comprehensive Cancer Network which asks patients to rate their distress on an ordinal scale of 0 (no distress) to 10 (extreme distress) [45]. A score of 3 or more has been used as a marker of significant distress [46]. This prompts patients to complete a 'problem list', choosing 'Yes' or 'No' for a number of potential biological, psychological and social stressors. Its simplicity and validation against the established HADS in cancer has made it a widely used clinical assessment tool, as advised in the NCCN Distress Management Guideline with potential utility as a research tool. It has been used in the assessment of DID in older patients following surgery [17].

The Edmonton Symptom Assessment [47] and later ESAS-revised [48] is a self-reported patient questionnaire where symptom intensity is graded on an eleven-point linear scale across nine domains in advanced cancer (pain, tiredness, nausea, depression, anxiety, drowsiness, appetite, well-being, shortness of breath, other). It is designed to be undertaken at various points through a patient's cancer journey and was developed by palliative care physicians. While it has been used to assess severity of symptoms in delirious patients, including anxiety, it is not validated as a score of severity of DID.

\section{Measuring distress in clinical research}

The single delirium-specific distress assessment tool available is the Delirium Experience Questionnaire (DEQ) [12]. This score was developed to assess patients' experiences after resolution of delirium and was used in conjunction with other scores (MDAS, Karnofsky Performance Status Scale) to assess predicting and correlating features for severity of DID. It was not, in its inception, validated against existing assessments scores for distress. The DEQ is a clinician-led questionnaire that asks six questions to patients regarding confusion, distress and recollection and a further two questions to relatives and care givers regarding their distress witnessing delirium. The score is given as either zero to moderate distress (0-2) or severe distress (3-4). Publications listed in Ovid databases MEDLINE(R), PsycINFO and PsycARTICLES until June 2019 included six further original research articles which use the DEQ [13, 34, 49-52]. Interestingly, none validate it against established anxiety/ distress scales. The single publication to review responses to the 'free text' question 6 reported hallucinations, fear and anxiety as common themes, consistent with the literature, although no qualitative analysis has been published from this [34].

Other recognised scores of agitation/distress include the Horowitz's Impact of Event Scale IES-6 [53], used mainly to understanding distress of events during ICU admission [54, 55], Psychological Distress Inventory [56], General Health Questionnaire 12 [57], Generalised Anxiety Disorder 7-item Scale (GAD-7) [58] and Structured Clinical Interview for the Diagnostic and Statistical Manual of Mental Disorders 
Fifth Edition (SCID-5) [59], and while these have been validated as distress scores in oncology and palliative care, they are not common in the literature assessing DID.

\section{Consequences of distress in delirium}

Distress in delirium occurs during the episode of delirium, can persist for months or years and is associated with longterm psychological morbidity. DID is not limited to the patients themselves; relatives or carers witnessing patients' delirium can also experience significant distress.

\section{Consequences for patients}

Patients experience long term psychological consequences from DID. There is an established association between ICUassociated delirium and PTSD symptoms in ICU survivors [35, 60, 61]. No significant association between delirium and PTSD has been shown; however, this could reflect ambiguities in diagnosis of delirium and differing clinical assessment tools [62, 63]. Persistent delusional memories have significant functional consequences for ICU survivors: those who experience delusional memories are less likely to have returned to work 6-12 months after the episode. After accounting for confounders such as retirement and non-completion for this question, $67 \%$ of the non-delusional memory group had returned to work compared to only $15 \%$ of those patients who could recall delusions, $p<0.01$ [64]. This trend was still present at $13-18$ months, although it no longer presented a significant difference.

\section{Consequences for relatives and informal carers}

Relatives experience distress in witnessing family members with delirium. In one qualitative study, $70 \%$ of families experienced distress at observing delirium in their relatives [21], while a similar study conducted with relatives of patients with advanced cancer diagnoses described 'stressful', 'terrible', 'frustrating' and 'scary' experiences [13].

Severity of relative distress is associated with specific delirium and patient factors, namely hyperactive delirium, presence of brain metastasis, witnessing labile affect, language disturbance, thought process disturbance, motor agitation, loss of orientation and previous diagnosis of cognitive decline $[12,17,30,52]$. Poor functional status was the only independent predictor patient-factor of spouse distress [12]. There is evidence to suggest that overall severity of the delirium witnessed also contributes to relative distress, although only identified among small numbers of participating relatives $[12,17]$.

Importantly, relatives' degree of distress can be higher than those reported by the patients themselves, and can cause relatives long term psychological harm. Buss et al. undertook structured interviews among a cross sectional of 200 caregivers of patients with delirium. Caregivers who perceived delirium in their relatives were 12 times more likely to develop generalised anxiety [65]. This relationship persisted despite accounting for carer burden and exposure to other stressful experiences. One study suggests that PTSD incidence among individuals whose relatives have survived an ICU admission was as high as $49 \%$, although this most likely reflects a combination of relatives' experience of patients being critically unwell, as well as their fluctuating recovery complicated by delirium [11].

\section{Consequences for healthcare staff}

Professional carers and healthcare staff experience distress when caring for patients with delirium. Two comprehensive reviews examine the breadth of qualitative research into experiences of patient delirium by nursing staff, reporting 'stress due to unpredictability of delirium and workload', concern over 'issues of safety' and 'understanding [delirious patients'] experiences' [66, 67]. Delirium-specific features causing significant distress for nurses, consistent across the literature, include psychomotor agitation, inattention or disorientation [12, 13, 49, 52].

$\mathrm{An}$ association has been reported between the extent and severity of the delirium episode and level of nursing distress [12]. However, this does not generalise to nurses working during day time hours (possibly due to variation in staffing levels and patients' day-night sleep disturbance) or those with greater training in delirium management [13].

\section{Management of distress in delirium}

While there is a significant body of literature investigating both management and prevention of delirium, the existing evidence for managing DID is limited. Current research focuses on information giving about delirium, before, during and after the event, and involving relatives in these interventions.

\section{Understanding delirium before it happens}

Early research into delirium suggested that education about delirium, before delirium presents, reduces the associated distress [68]. 64 patients undergoing cardiac surgery were assigned to educational intervention delivered by a researcher, who explains perceptual disturbances, and changes in cognition and concentration common in delirium, or to a control group. In post-operative interviews there 
was no significant difference in the occurrence of 'unusual experiences' between groups, but those who received the educational intervention reported significant differences in feeling more 'comfortable' during these episodes.

\section{Information during episode}

Giving information to patients with delirium can be problematic due to reduced concentration and cognitive function. In the absence of clear evidence that education during delirium reduces patient-related distress, the focus remains on post episode interventions. This relies on identifying who would benefit from an intervention, when this should be delivered and what such an intervention should consist of [66]. There is evidence to suggest that patients want more information about symptoms of delirium $[14,69,70]$ and patients report that knowing about the delirium and plans for their care and helps them to feel safe and reassured [69]. Such themes could be incorporated into a post-episode delirium related distress intervention.

Reducing relative distress is also key to treating DID, which, as explored above, can be more extreme than that experienced by the patient themselves. Relatives and caregivers also want support and advice on how to respond to patients with delirium [70]. In their survey of relatives' understanding of delirium, Bull et al. concluded that prior knowledge about delirium in caregivers may reduce their distress. However, any proposed educational intervention may need to be timed effectively in order to reduce distress: relatives given educational material at some point before or during a patients' delirium episode were more knowledgeable about delirium, but had no difference in their perceived distress [71]. Communication aids, in conjunction with educational resources, may be relevant for reducing distress [21].

\section{Information following the event}

There is an established practice in ICU to compile abbreviated, de-jargonised clinical 'diaries' for patients to discuss at appointments following discharge. Jones et al. [10] showed in a randomised control trial that discussing diaries at one month can reduce the incidence of new PTSD following ICU stay. However, systematic reviews of the evidence base for these diaries show, in general, small cohorts with varying methodology and uncertain generalisation across all patient groups in the ICU [72-74]. One 'pragmatic' randomised control trial of nurse-led follow up showed no evidence of improved physical or psychological health at 12 months in the intervention group [75]. In the UK, the implementation of generalised outpatient 'debriefing' post ICU and critical care admission is founded on expert opinion [76]. The approach of diaries and debriefing has been suggested for patients who have recovered from delirium [66]. While there remains insufficient evidence to generalise this to patients who have experienced delirium, regardless of the aetiology, in general this remains a possibility for future research in the management of DID.

There is clear need to improve patients' understanding of delirium: at one year follow up, structured interviews with 49 cardiac patients diagnosed with post-operative delirium, showed that many of the patients did not identify with the diagnosis of 'delirium', yet described many features associated with delirium [77]. This highlights the importance of education around delirium, and reducing the associated stigma.

Qualitative research exploring the views of patients and relatives in order to co-design interventions to reduce DID found that patients and relatives themselves had clear views about potential interventions to minimise this distress (under review). These included discussions of postoperative delirium, with patients as well as in the wider public sphere, and the provision of specific information on the harm delirium could cause (risk and causes of delirium, the expected recovery from delirium etc.), delivered by a trained person.

\section{Summary}

This review summarises the risk factors, assessments and current approaches for understanding and managing DID, collating evidence from a number of healthcare settings. Both patient and delirium specific factor contribute to higher levels of distress. DID exists not only during the episode of delirium, but can persist for months and years and is associated with long term psychological morbidity. Similarly, DID is not limited to the patients themselves: relatives or carers witnessing patients' delirium can also experience significant distress, sometimes more pronounced than for the patient themselves. When evaluating the severity of distress, a number of assessment tools have been developed. However, only a few have been validated and adopted in research and clinical practice, and there is no current consensus on which tool should be used. Interventions to reduce DID focus on information giving about delirium, before, during and after the event, and for patients and relatives. Future strategies will need to adopt systematic methods for identifying patients at risk of delirium and, provide information before and after the episode of delirium.

Funding No funding was received. 


\section{Compliance with ethical standards}

Conflict of interest On behalf of the authors, the corresponding author states that there is no conflict of interest.

Ethical approval This article does not contain any studies with human participants or animals performed by any of the authors.

Informed consent For this retrospective review, formal consent is not required.

Open Access This article is licensed under a Creative Commons Attribution 4.0 International License, which permits use, sharing, adaptation, distribution and reproduction in any medium or format, as long as you give appropriate credit to the original author(s) and the source, provide a link to the Creative Commons licence, and indicate if changes were made. The images or other third party material in this article are included in the article's Creative Commons licence, unless indicated otherwise in a credit line to the material. If material is not included in the article's Creative Commons licence and your intended use is not permitted by statutory regulation or exceeds the permitted use, you will need to obtain permission directly from the copyright holder. To view a copy of this licence, visit http://creativecommons.org/licenses/by/4.0/.

\section{References}

1. American Psychiatric Association (2013) Diagnostic and statistical manual of mental disorders. 5th ed. Washington, DC

2. National Institute of Clinical Excellence (2010) Delirium: diagnosis, prevention and management CG103, London

3. Diwell RA, Davis DH, Vickerstaff V, Sampson EL (2018) Key components of the delirium syndrome and mortality: greater impact of acute change and disorganised thinking in a prospective cohort study. BMC Geriatr [Internet]. BioMed Central 18:24. https://www.ncbi.nlm.nih.gov/pubmed/29370764

4. McCusker J, Cole MG, Dendukuri N, Belzile E (2003) Does delirium increase hospital stay? J Am Geriatr Soc [Internet]. John Wiley \& Sons, Ltd (10.1111); 51:1539-1546. https://doi. org/10.1046/j.1532-5415.2003.51509.x

5. Rizzo JA, Bogardus STJ, Leo-Summers L, Williams CS, Acampora D, Inouye SK (2001) Multicomponent targeted intervention to prevent delirium in hospitalized older patients: what is the economic value? Med Care [Internet] 2001:39. https:// journals.lww.com/lww-medicalcare/Fulltext/2001/07000/Multi component_Targeted_Intervention_to_Prevent.10.aspx

6. Pérez-Ros P, Martínez-Arnau FM (2019) Delirium assessment in older people in emergency departments. A literature review. Dis (Basel, Switzerland) [Internet]. MDPI; 7:14. https://www. ncbi.nlm.nih.gov/pubmed/30704024

7. Van Rompaey B, Van Hoof A, van Bogaert P, Timmermans O, Dilles T (2016) The patient's perception of a delirium: a qualitative research in a Belgian intensive care unit. Intensive Crit Care Nurs [Internet]. Churchill Livingstone; 32:66-74. https:// www.sciencedirect.com/science/article/pii/S09643397150002 1X?via\%3Dihub. Accessed 29 Apr 2019

8. Kiekkas P, Theodorakopoulou G, Spyratos F, Baltopoulos G (2010) Psychological distress and delusional memories after critical care: a literature review. Int Nurs Rev 57:288-296

9. Samuelson K, Lundberg D, Fridlund B (2006) Memory in relation to depth of sedation in adult mechanically ventilated intensive care patients. Intensive Care Med 32:660-667

10. Jones C, Griffiths RD, Humphris G, Psych C, Skirrow PM (2001) Memory, delusions, and the development of acute posttraumatic stress disorder-related symptoms after intensive care. Crit Care 29:573-580

11. Jones C, Bäckman C, Capuzzo M, Flaatten H, Rylander C, Griffiths RD (2007) Precipitants of post-traumatic stress disorder following intensive care: a hypothesis generating study of diversity in care. Intensive Care Med 33:978-985

12. Breitbart W, Gibson C, Tremblay A (2002) The delirium experience: delirium recall and delirium-related distress in hospitalized patients with cancer, their spouses/caregivers, and their nurses. Psychosomatics, Elsevier BV 43:183-194

13. Bruera E, Bush SH, Willey J, Paraskevopoulos T, Li Z, Palmer JL et al (2009) Impact of Delirium and recall on the level or distress in patients with advanced cancer and their family caregivers. Cancer 115:2004-2012

14. Duppils GS, Wikblad K (2004) Cognitive function and healthrelated quality of life after delirium in connection with hip surgery. A six-month follow-up. Orthop Nurs [Internet] 23:195203. http://www.ncbi.nlm.nih.gov/pubmed/15211901

15. Blank K, Perry S (1984) Relationship of psychological processes during delirium to outcome. Am J Psychiatry 141:843-847

16. Partridge JSL, Dhesi JK, Cross JD, Lo JW, Taylor PR, Bell R et al (2014) The prevalence and impact of undiagnosed cognitive impairment in older vascular surgical patients. J Vasc Surg [Internet]. Society for Vascular Surgery 60:1002-1011. e3. http://dx.doi.org/10.1016/j.jvs.2014.04.041

17. Partridge JSL, Crichton S, Biswell E, Harari D, Martin FC, Dhesi JK (2019) Measuring the distress related to delirium in older surgical patients and their relatives. Int J Geriatr Psychiatry [Internet]. https://doi.org/10.1002/gps.5110

18. Boorsma M, Joling KJ, Frijters DHM, Ribbe ME, Nijpels G, Van Hout HPJ (2012) The prevalence, incidence and risk factors for delirium in Dutch nursing homes and residential care homes. Int J Geriatr Psychiatry [Internet] 27:709-715. https:// doi.org/10.1002/gps. 2770

19. Flaherty JH, Morley JE (2013) Delirium in the nursing home. J Am Med Dir Assoc 14:632-634 (Elsevier BV)

20. Mercadante S, Masedu F, Maltoni M, De Giovanni D, Montanari L, Pittureri C et al (2018) Symptom expression in advanced cancer patients admitted to hospice or home care with and without delirium. Intern Emerg Med (Springer Italia s.r.l.)

21. Namba M, Morita T, Imura C, Kiyohara E, Ishikawa S, Hirai K (2007) Terminal delirium: families' experience. Palliat Med 21:587-594

22. Mcnicoll L, Pisani MA, Zhang Y, Wesley Ely E, Siegel MD, Inouye SK (2003) Delirium in the intensive care unit: occurrence and clinical course in older patients. J Am Geriatrics Soc 51:591-598

23. Ringdal M, Johansson L, Lundberg D, Bergbom I (2006) Delusional memories from the intensive care unit-experienced by patients with physical trauma. Intensive Crit Care Nurs [Internet] 22:346-54. http://www.sciencedirect.com/science/article/ pii/S0964339706000371

24. Rundshagen I, Schnabel K, Wegner C, Schulte EJ (2002) Incidence of recall, nightmares, and hallucinations during analgosedation in intensive care. Intensive Care Med. 28:38-43

25. Puntillo KA, Arai S, Cohen NH, Gropper MA, Neuhaus J, Paul SM et al (2010) Symptoms experienced by intensive care unit patients at high risk of dying. Crit Care Med 38:2155-2160

26. Wade DM, Howell DC, Weinman JA, Hardy RJ, Mythen MG, Brewin CR et al (2012) Investigating risk factors for psychological morbidity three months after intensive care: a prospective cohort study. Crit Care [Internet]. BioMed Central Ltd 16:R192. http://ccforum.com/content/16/5/R192

27. Wade D, Hardy R, Howell D, Mythen M (2013) Identifying clinical and acute psychological risk. Minerva Anestesiol 79:944-963 
28. van den Boogaard M, Schoonhoven L, Evers AWM, van der Hoeven JG, van Achterberg T, Pickkers P (2012) Delirium in critically ill patients: impact on long-term health-related quality of life and cognitive functioning. Crit Care Med [Internet] 40:112-118. http://www.ncbi.nlm.nih.gov/pubmed/21926597

29. Vasilevskis EE, Han JH, Hughes CG, Ely EW (2012) Epidemiology and risk factors for delirium across hospital settings. Best Pract Res Clin Anaesthesiol [Internet] 26:277-287. http://www. sciencedirect.com/science/article/pii/S1521689612000365

30. Morita T, Hirai K, Sakaguchi Y, Tsuneto S, Shima Y (2004) Family-perceived distress from delirium-related symptoms of terminally ill cancer patients. Psychosomatics [Internet] 45:107-13. http://www.sciencedirect.com/science/article/pii/ S0033318204702042

31. Finucane AM, Lugton J, Kennedy C, Spiller JA (2017) The experiences of caregivers of patients with delirium, and their role in its management in palliative care settings: an integrative literature review. Psychooncology [Internet]. 26:291-300 (John Wiley and Sons Inc.). https://www.ncbi.nlm.nih.gov/pubme $\mathrm{d} / 27132588$

32. Breitbart W, Rosenfeld B, Roth A, Smith MJ, Cohen K, Passik S (1997) The memorial delirium assessment scale. J Pain Symptom Manage 13:128-137

33. Trzepacz PT, Mittal D, Torres R, Kanary K, Norton J, Jimerson $\mathrm{N}$ (2001) Validation of the delirium rating scale-revised-98. J Neuropsychiatry Clin Neurosci [Internet] 13:229-42 (American Psychiatric Publishing). https://doi.org/10.1176/jnp.13.2.229

34. Grover S, Ghosh A, Ghormode D (2014) Experience in delirium: is it distressing? J Neuropsychiatry Clin Neurosci 27:139-146

35. Roberts BL, Rickard CM, Rajbhandari D, Reynolds P (2007) Factual memories of ICU: recall at two years post-discharge and comparison with delirium status during ICU admissiona multicentre cohort study. J Clin Nurs [Internet] 16:16691677 (John Wiley \& Sons, Ltd). https://doi.org/10.111 1/j.1365-2702.2006.01588.x

36. Pandharipande PP, Girard TD, Jackson JC, Morandi A, Thompson JL, Pun BT et al (2013) Long-term cognitive impairment after critical illness. N Engl J Med [Internet] 369:1306-1316. https ://doi.org/10.1056/nejmoa1301372 (Massachusetts Medical Society)

37. Davis DHJ, Muniz Terrera G, Keage H, Rahkonen T, Oinas M, Matthews FE et al (2012) Delirium is a strong risk factor for dementia in the oldest-old: a population-based cohort study. Brain [Internet] 135:2809-2816 (Oxford University Press). https://www. ncbi.nlm.nih.gov/pubmed/22879644

38. Saczynski JS, Marcantonio ER, Quach L, Fong TG, Gross A, Inouye SK et al (2012) Cognitive trajectories after postoperative delirium. N Engl J Med [Internet] 367:30-39. http://www.ncbi. nlm.nih.gov/pubmed/22762316\%0Ahttp://www.pubmedcentral. nih.gov/articlerender.fcgi?artid=PMC3433229

39. Davis DHJ, Muniz-Terrera G, Keage HAD, Stephan BCM, Fleming J, Ince PG et al (2017) Association of delirium with cognitive decline in late life: a neuropathologic study of 3 population-based cohort studies. JAMA Psychiatry. 74:244-251

40. Mitchell AJ (2010) Short screening tools for cancer-related distress: a review and diagnostic validity meta-analysis. JNCCN J Natl Compr Cancer Netw 8:487-494

41. Zigmond AS, Snaith RP (1983) The hospital anxiety and depression scale. Acta Psychiatr Scand [Internet] 67:361-370. https:// doi.org/10.1111/j.1600-0447.1983.tb09716.x

42. Herrmann C (1997) International experiences with the hospital anxiety and depression scale-a review of validation data and clinical results. J Psychosom Res 42:17-41
43. Bjelland I, Dahl AA, Tangen T, Neckelmann D (2002) The validity of the Hospital Anxiety and Depression Scale: an updated literature review. J Psychosom Res 52:69-77

44. Mitchell AJ, Kaar S, Coggan C, Herdman J (2008) Acceptability of common screening methods used to detect distress and related mood disorders-preferences of cancer specialists and nonspecialists. Psychooncology [Internet]. 17:226-236. https://doi. org/10.1002/pon.1228

45. NCCN.org. (2019) National Comprehensive Cancer Network Clinical Practice Guidelines in Oncology (NCCN Guidelines): Distress Management [Internet]. version 3. https://www.nccn.org/ professionals/physician_gls/pdf/distress.pdf

46. Cutillo A, O'Hea E, Person S, Lessard D, Harralson T, Boudreaux E (2017) The distress thermometer: cutoff points and clinical use. Oncol Nurs Forum [Internet] 44:329-336. http://onf.ons.org/ onf/44/3/distress-thermometer-cutoff-points-and-clinical-use

47. Bruera E, Kuehn N, Miller MJ, Selmser P, Macmillan K (1991) The Edmonton symptom assessment system (ESAS): a simple method for the assessment of palliative care patients. J Palliat Care [Internet] 7:6-9 (SAGE Publications Inc). https://doi. org/10.1177/082585979100700202

48. Watanabe S, Nekolaichuk C, Beaumont C (2012) The Edmonton Symptom Assessment System, a proposed tool for distress screening in cancer patients: development and refinement. Psychooncology. 21:977-985

49. Morandi A, Lucchi E, Turco R, Morghen S, Guerini F, Santi R et al (2015) Delirium superimposed on dementia: a quantitative and qualitative evaluation of patient experience. J Psychosom Res [Internet] 79:281-287. https://www.ncbi.nlm.nih.gov/pubme $\mathrm{d} / 26282373$

50. Grover S, Shah R (2011) Distress due to delirium experience. Gen Hosp Psychiatry 33:637-639 (Elsevier Inc.)

51. Hui D, Dev R, Bruera E (2016) Neuroleptics in the management of delirium in patients with advanced cancer. Curr Opin Support Palliat Care [Internet] 10:316-323. https://doi.org/10.1016/j.jpain symman.2009.07.009 (Elsevier Inc)

52. Martins S, Pinho E, Correia R, Moreira E, Lopes L, Paiva JA et al (2018) What effect does delirium have on family and nurses of older adult patients? Aging Ment Heal. 22:903-911

53. Sundin EVAC, Horowitz MJ (2012) Impact of Event Scale: psychometric properties. Br J Psychiatry 2012:205-209

54. Talisayon R, Buckley T, McKinley S (2011) Acute post-traumatic stress in survivors of critical illness who were mechanically ventilated: a mixed methods study. Intensive Crit Care Nurs [Internet] 27:338-346. https://doi.org/10.1016/j.iccn.2011.10.001 (Elsevier Ltd)

55. Rattray J, Crocker C, Jones M, Connaghan J (2010) Patients' perceptions of and emotional outcome after intensive care: results from a multicentre study. Nurs Crit Care. 15:86-93

56. Morasso G, Baracco G, Borreani C., Capelli M, Costantini M (1996) Clinical study assessing psychological distress in cancer patients: validation of a self-administered questionnaire [Internet]. Oncology. http://www.kargcr.ch

57. Goldberg DP (1978) Manual of the general health questionnaire. NFER Publishing, Windsor

58. Spitzer RL, Kroenke K, Williams JBW, Löwe B (2018) A brief measure for assessing generalized anxiety disorder the GAD-7 [Internet]. https://jamanetwork.com/

59. Kelly B, McClement S, Chochinov HM (2006) Measurement of psychological distress in palliative care. Palliat Med [Internet] 20:779-789. https://doi.org/10.1177/0269216306072347

60. Girard TD, Shintani AK, Jackson JC, Gordon SM, Pun BT, Henderson MS et al (2007) Risk factors for post-traumatic stress disorder symptoms following critical illness requiring mechanical ventilation: a prospective cohort study. Crit Care 11:1-8 
61. DiMartini A, Amanda Dew M, Kormos R, McCurry K, Fontes P (2007) Posttraumatic stress disorder caused by hallucinations and delusions experienced in delirium. Psychosomatics 48:436-439 (Elsevier BV)

62. Davydow DS, Gifford JM, Desai SV, Needham DM, Bienvenu OJ (2008) Posttraumatic stress disorder in general intensive care unit survivors: a systematic review. Gen Hosp Psychiatry 30:421-434

63. Davydow DS, Zatzick DF, Rivara FP, Jurkovich GJ, Wang J, RoyByrne PP et al (2009) Predictors of posttraumatic stress disorder and return to usual major activity in traumatically injured intensive care unit survivors. Gen Hosp Psychiatry [Internet] 31:42835. https://www.ncbi.nlm.nih.gov/pubmed/19703636

64. Ringdal M, Johansson L, Lundberg D, Bergbom I (2006) Delusional memories from the intensive care unit-Experienced by patients with physical trauma. Intensive Crit Care Nurs 22:346-354

65. Buss MK, Vanderwerker LC, Inouye SK, Zhang B, Block SD, Prigerson HG (2007) Associations between caregiver-perceived delirium in patients with cancer and generalized anxiety in their caregivers. J Palliat Med. 10:1083-1092

66. O'Malley G, Leonard M, Meagher D, O'Keeffe ST (2008) The delirium experience: a review. J Psychosom Res 2008:223-228

67. Bélanger L, Ducharme F (2011) Patients' and nurses' experiences of delirium: a review of qualitative studies. Nurs Crit Care [Internet] 16:303-315. https://doi.org/10.1111/j.1478-5153.2011.00454 .x (John Wiley \& Sons, Ltd (10.1111))

68. Owens J, Hutelmyer C (1982) The effect of preoperative intervention on delirium in cardiac surgical patients. Nurs Res 31:60-62

69. Laitinen H (1996) Patients' experience of confusion in the intensive care unit following cardiac surgery. Intensive Crit Care Nurs 12:79-83

70. Magarey JM, McCutcheon HH (2005) "Fishing with the dead"recall of memories from the ICU. Intensive Crit Care Nurs 21:344-354

71. Otani H, Morita T, Uno S, Yamamoto R, Hirose H, Matsubara T et al (2014) Effect of leaflet-based intervention on family members of terminally ill patients with cancer having delirium: historical control study. Am J Hosp Palliat Med 31:322-326

72. Ullman AJ, Aitken LM, Rattray J, Kenardy J, Le Brocque R, MacGillivray $S$ et al (2015) Intensive care diaries to promote recovery for patients and families after critical illness: a cochrane systematic review. Int J Nurs Stud [Internet] 52:1243-1253. https ://doi.org/10.1016/j.ijnurstu.2015.03.020 (Elsevier Ltd)

73. Aitken LM, Rattray J, Hull A, Kenardy JA, Le Brocque R, Ullman AJ (2013) The use of diaries in psychological recovery from intensive care. Crit Care [Internet]. BioMed Central 17:253. https ://www.ncbi.nlm.nih.gov/pubmed/24351578

74. Vijayaraghavan BKT, Willaert X, Cuthbertson BH (2018) Should ICU clinicians follow patients after ICU discharge? No. Intensive Care Med. 44:1542-1544 (Springer Nature America, Inc)

75. Cuthbertson BH, Rattray J, Johnston M, Wildsmith JA, Wilson E, Hernendez R et al (2007) A pragmatic randomised, controlled trial of intensive care follow up programmes in improving Longer-term outcomes from critical illness. The PRACTICAL study. BMC Health Serv Res 7:1-6

76. Modernisation Agency National Health Service (2003) Progress in developing services: critical care outreach 2003. London

77. Lingehall HC, Smulter NS, Lindahl E, Lindkvist M, Engström KG, Gustafson YG et al (2017) Preoperative cognitive performance and postoperative delirium are independently associated with future dementia in older people who have undergone cardiac surgery. Crit Care Med [Internet] 45:1295-1303. http://insights. ovid.com/crossref?an=00003246-201708000-00005

Publisher's Note Springer Nature remains neutral with regard to jurisdictional claims in published maps and institutional affiliations. 